\section{The effect of corrective exercises on functional movement screen test and motor skills}

\section{Düzeltici egzersizlerin fonksiyonel hareket tarama testi ve motor beceri üzerine etkisi $^{1}$}

\author{
Şeyda Nur Usluer ${ }^{2}$ \\ Zait Burak Aktuğ ${ }^{3}$ \\ Serkan İbiş ${ }^{4}$ \\ Hasan Aka ${ }^{5}$
}

\begin{abstract}
The aim of this study is to examine the effect of 8-week corrective exercises applied to 12-15 age group basketball players on Functional Movement Screen Test (FMS) and motor skill (MS) score. 65 volunteer children between the ages of 12-15 participated in the study. The children were the control group (CG) $(\mathrm{N}=25)$ who did not do any exercise, the basketball group that only trained basketball $(\mathrm{BG})(\mathrm{N}=$ 20 ), and the corrective exercise group (CEG) $(\mathrm{N}$ $=20)$ that did corrective exercises in addition to basketball training. It is divided into 3 groups. Basketball training was applied to children on BG 3 days a week. In addition to basketball training, an 8-week corrective exercise protocol was applied to the children in CEG. Functional movement patterns of children were determined with FMS test and MSs with Deutscher Motor Test (DMT). Kruskal-Wallis
\end{abstract}

\section{Özet}

$\mathrm{Bu}$ çalışmasının amacı, 12-15 yaş grubu basketbolculara uygulanan 8 haftalık düzeltici egzersizlerin fonksiyonel hareket tarama testi (FHT) ve motor beceri (MB) puanı üzerine etkisinin incelenmesidir. Çalışmaya $12-15$ yaş aras1 65 gönüllü çocuk katılmıştır. Çocuklar herhangi bir egzersiz yapmayan kontrol grubu (KG) $(\mathrm{N}=25)$, sadece basketbol antrenmanı yapan basketbol grubu (BG) $(\mathrm{N}=20)$ ve basketbol antrenmanına ilaveten düzeltici egzersiz yapan düzeltici egzersiz grubu (DEG) $(N=20)$ olmak üzere 3 gruba ayrılmıştır. BG'da bulunan çocuklara haftada 3 gün sadece basketbol antrenmanı, DEG'da bulunan çocuklara basketbol antrenmanlarına ilaveten 8 haftalı düzeltici egzersiz protokolü uygulanmıştır. Çocukların fonksiyonel hareket kaliplar1 FHT testi ile MB'leri Deutscher Motor Testi (DMT) ile belirlenmiştir. Çocukların FHT

\footnotetext{
${ }^{1}$ Bu çalışma Niğde Ömer Halisdemir Üniversitesi, Sosyal Bilimler Enstitüsü, Beden Eğitimi ve Spor A.B.D'da Yüksek Lisans tezi olarak sunulmuştur.

2 Lisansüstü Öğrencisi. Niğde Ömer Halisdemir Üniversitesi, Sosyal Bilimler Enstitüsü (iD) Orcid ID: 0000-0003-2462-2413 seydasvr151@gmail.com

3 Doç. Dr. Niğde Ömer Halisdemir Üniversitesi, Spor Bilimleri Fakültesi, (D) Orcid ID: 0000-0002-5102-4331 zaitburak@gmail.com

4 Prof. Dr. Niğde Ömer Halisdemir Üniversitesi, Spor Bilimleri Fakültesi, (D) Orcid ID: 0000-0002-5154-3086 serkanibis@gmail.com

5 Doç. Dr. Niğde Ömer Halisdemir Üniversitesi, Spor Bilimleri Fakültesi, (D) Orcid ID: 0000-0003-0603-9478 hasanaka06@gmail.com
} 
Usluer, Ș. N., Aktuğ, Z. B., İbiş, S., \& Aka, H. (2021). Düzeltici egzersizlerin fonksiyonel hareket tarama testi ve motor beceri üzerine etkisi. Journal of Human Sciences, 18(3), 390-399. doi:10.14687/jhs.v18i3.6154

$\mathrm{H}$ Test was used to determine the differences children's pre-tests and post-tests after corrective exercises. As a result of the statistical analysis, a statistically significant difference was found between the pre-test and post-tests of FMS total scores and DMT scores in CEG $(p<0.05)$. As a result, it has been shown that corrective exercises contribute to FMS total scores and the MS development of children. It is thought that the placement of corrective exercises in the training contents can increase the MSs of children.

Keywords: Functional movement screening; motor skill; corrective exercises.

(Extended English summary is at the end of this document) skorları ve DMT skorlarının ön testleri ile düzeltici egzersizler sonras1 son testleri arasındaki fark1 belirlemede Wilcoxon İşaretli Sıralar Testi kullanılmıştır. İstatiksel analizler sonucunda, DEG'da FHT toplam skorları ve DMT skorları ön test ile son testleri arasinda istatiksel olarak anlamlı bir farkl1lık bulunmuştur $(p<0,05)$. Sonuç olarak düzeltici egzersizlerin FHT toplam skorlanna ve çocukların MB gelişimine katk1 sağladığ1 gösterilmiştir. Düzeltici egzersizlerin antrenman içeriklerine yerleştirilmesinin çocukların MB'lerini artırabileceği düşünülmektedir.

Anahtar Kelimeler: Fonksiyonel hareket taramas1; motor beceri; düzeltici egzersizler.

\section{Giriş}

Motor Beceri (MB), bireyin tüm yaşamı boyunca fiziksel ve psikolojik durumunda önemli rol oynayan (Cattuzzo ve ark., 2016; Robinson ve ark., 2015) ve birçok motor görevin yanı sıra hareket kalitesi, koordinasyon ve kontrol becerileri ile ilgili bir terimdir (Robinson ve ark., 2015). Bireylerin MB yetenekleri; zeka, yaş, motivasyon, yorgunluk ve çevresel faktörlerden etkilendiği gibi sportif aktivitelere katilım düzeyi de (kondisyon düzeyi, antrenman durumu) bu becerileri etkilemektedir (Sayın, 2011; Timmons ve ark., 2007; Pişkin ve ark., 2020). Özellikle çocukların MB yetenekleri, genel gelişimlerinin belirleyicileri olup (Haga, 2008; Henderson ve Sugden, 1992) sağlıklı olmanın da önemli belirteçlerindendir (Stodden ve ark., 2008). Motor beceriler genellikle adolesan dönemde gelişmeye başlamaktadır. Motor becerisi erken gelişen adolesan bir sporcu; aynı kronolojik yaştaki sporcuya göre daha verimli bir performans sergilemektedir (Patel ve ark., 2017). Ayrıca aynı kronolojik yaş aralığında bulunan adolesan sporculardan; denge, koordinasyon ve alg1 yeteneği henüz gelişmeye başlamayanların, antrenman ve müsabakalarda yaralanma riski artmaktadır (Brukner, 2012; O'Kane ve ark., 2017). Bu dönemdeki sporcularda teknik, taktik, beceri eksikliği, yüksek riskli hareketleri yapma eğilimi, çevresel koşullardaki deneyimsizlikler de spor yaralanmalarının görülme sıklığını artırmaktadır (Mirhadi ve ark., 2015).

Sporcuların yaralanma olasılıklarının belirlenmesi, koruyucu stratejiler geliştirilmesi ve performans verimliliği açısından oldukça önemlidir (Kiesel ve ark., 2007). Fonksiyonel Hareket Tarama testi, sporcularda oluşabilecek yaralanmaların tahmin edilmesinde hızlı ve kolay bir şekilde uygulanabilen bir tarama aracidır. FHT test bataryası sporculardaki temel hareket paternlerinin basit yöntemlerle güvenilir bir şekilde değerlendirilmesine imkan sağlar (Kraus ve ark., 2014; Onate ve ark., 2012; Minick ve ark., 2010). FHT ile yapılan değerlendirmelerde, fonksiyonel hareket kalıplarındaki kısıtllılık, asimetri ve işlevsizlikler tespit edilir (Chorba ve ark., 2010). Sporcuların fonksiyonel hareket kalıpları kötü ise bu durum sporcunun performansını kısıtlar ve yaralanma riskini artırabilir (Kiesel ve ark., 2007). Verimli bir fonksiyonel hareket için uygun düzeyde stabilite ve mobilite gerekmektedir (Hamilton ve ark., 2002).

Sporcuların fonksiyonel hareket paternlerinin erken yaşlarda geliştirilmesiyle, doğru hareket kalıplarının uygulanması ve buna bağlı olarak performans verimliliğinin artacağı düşünülmektedir. Fonksiyonel hareket paternlerinin geliştirilebilir olduğu ve düzeltici egzersizlerin de foksiyonel hareket paternlerini geliştirilmede kullanılabileceği bilinmektedir (Mokha ve ark., 2016). Düzeltici egzersizler, sporcuların işlevsiz olan fonksiyonel hareket kalıplarına yönelik olarak hazırlanarak hareketlerdeki 
Usluer, Ş. N., Aktuğ, Z. B., İbiş, S., \& Aka, H. (2021). Düzeltici egzersizlerin fonksiyonel hareket tarama testi ve motor beceri üzerine etkisi. Journal of Human Sciences, 18(3), 390-399. doi:10.14687/jhs.v18i3.6154

asimetrileri azaltabilir (Aktuğ ve ark., 2019). Ayrıca düzeltici egzersizlerin sporcularda temel hareket kalıplarını geliştirirken aynı zamanda MB’lerini de geliştireceği düşünülmektedir. Literatürde düzeltici egzersizlerin temel hareket kalıplarına etkisini araştıran sınırlı sayıda çalışma olduğu görülmektedir (Aktuğ ve ark., 2019). Düzeltici egzersizler ile MB’lerin geliştirilmesine yönelik bir çalısma ise bulunmamaktadır. Bu bağlamda çalışmamızın amacı, genç basketbolculara uygulanan düzeltici egzersizlerin FHT ve MB test puanlarına etkisinin incelenmesidir.

\section{Materyal ve Metot}

Çalışmada deneme modellerinden ön test-son test ölçümleri içeren kontrol gruplu model kullanılmıştır. Katılımcılar yansız atama yolu ile Düzeltici Egzersiz Grubu (DEG), Kontrol Gurubu (KG) ve Basketbol Grubu (BG) olarak ayrılmıştır. DEG katılımcıları 8 haftalık bir süreçte haftada 3 gün rutin antrenmanlarına ilaveten düzeltici egzersiz protokolüne katılmıştır. BG katılımcıları bu süreçte sadece basketbol yaz okulundaki antrenman programına katılmışlardır. KG'na ise herhangi bir uygulama yapılmamıştır. Katılımcıların üç gruba ayrılmasının amacı, çalışmanın hipotezine göre oluşabilecek gelişmelerin, çocukların gelişim dönemleri nedeniyle mi?, basketbol antrenmanları nedeniyle mi? ya da uygulanan düzeltici egzersizler sonucu mu? kaynaklandığını tespit etmektir.

\subsection{Evren ve Örneklem}

Çalışmanın evrenini, Niğde ilinde 12-15 yaş arasındaki sedanter çocuklar ve Niğde Gençlik ve Spor İl Müdürlüğü’ne bağlı Gençlik Hizmetleri ve Spor Kulübü’nde yaz okuluna katılan 12-15 yaş grubu çocuklar oluştururken, örneklemini ise ulaşlabilir evren içerisinden seçilen toplam 65 sedanter ve basketbol yaz okuluna katılan çocuk oluşturmaktadır. Çalışma öncesinde katılımcıların her birine çalışma ile ilgili ayrıntlı bilgi verilip, Bilgilendirilmiş Gönüllü Olur Formu ve Veli İzin Belgesi imzalatılmıştır. Araştırma için Niğde Ömer Halisdemir Üniversitesi Etik Kurulu'ndan yazılı izin alınmıştur.

\subsection{Veri Toplama Teknikleri}

\subsubsection{Fonksiyonel Hareket Tarama Testi (FHT)}

Fonksiyonel Hareket Taraması testi Fonksiyonel Hareket Tarama Test bataryası kullanılarak belirlenmiştir. Uygulanan testteki hareketler sırasıyla, derin çömelme, yüksek adımlama, tek çizgide hamle, omuz mobilitesi, aktif düz bacak kaldırma, gövde stabilite şınavı, rotasyon satbilitesidir. Katılımcılar ısınma yapmadan vücutlarının bazal durumu dikkate alınarak ölçümler yapılmıştur. Testin uygulanması sırasında her hareket üç kez tekrarlanmıştır. Testte ilk olarak tek taraflı olarak değerlendirilen hareketler (derin çömelme, gövde stabilite şınavı) ölçülmüştür. Her iki tarafı da ölçen testler; (yüksek adımlama, tek çizgide hamle, omuz mobilitesi, aktif düz bacak kaldırma ve rotasyon stabilitesi) sağ ve sol olarak ayrı ayrı skorlandırılmıştır. Puanlama sırasında katılımcıların vücutlarının her iki yönden aldığı puanlar kaydedilmiştir. Ancak hareketten aldığı en düşük puan test sonucu olarak kabul edilmiştir. Her test kendi içinde 0 ile 3 arasında puanlanmıştır. En yüksek FHT test puanı 21'dir. FHT toplam puanı 14 puanın altında olan katılımcıların, 14 puanın üzerinde olanlara göre daha yüksek yaralanma riskine sahip olduğu bilinmektedir (Cook ve ark., 2006).

\subsubsection{Deutscher Motor Testi (DMT)}

Deutscher Motor Testi (DMT) 6-18 yaş arası çocuk ve ergenlerin MB’lerinin ölçülmesine ve değerlendirilmesine izin veren özel bir testtir. DMT, Alman Spor Bilimleri Derneği'nin önde gelen uzmanları tarafından geliştirilmiştir (Bos ve ark., 2009). DMT 8 farklı testten oluşmaktadır. Bunlardan 7 tanesi kurulan istasyonlarla tek tek yapilırken $(20 \mathrm{~m}$ sürat, denge, yanlara sıçrama, durarak uzun atlama, mekik, şınav, esneklik), son test olan $6 \mathrm{dk}$ koşu testi grup halinde uygulanmaktadır. Her test aşamasında testin sonucunda kaydedilen ve test protokol kâğıdına işlenen puanlar, DMT değerlendirme tablolanına göre yorumlanmıştır. 
Usluer, Ş. N., Aktuğ, Z. B., İbiş, S., \& Aka, H. (2021). Düzeltici egzersizlerin fonksiyonel hareket tarama testi ve motor beceri üzerine etkisi. Journal of Human Sciences, 18(3), 390-399. doi:10.14687/jhs.v18i3.6154

\subsubsection{Uygulanan Düzeltici Egzersiz Protokolü}

Düzeltici egzersiz grubu katılımcilarına egzersizler 8 hafta boyunca haftada 3 gün antrenman öncesinde ve basketbol antrenmanı aksatmayacak şekilde uygulanmıştır. Düzeltici egzersiz grubuna basketbol antrenmanından önce tam dinlenme uygulanmıştır. Çalışmamızda onlarca FHT düzeltici egzersizi arasından seçilen ve katılımcılarının FHT skorları ön test sonuçlarına göre katılımcının eksiklerini geliştireceği düşünülen hareketlerden oluşan bir protokol uygulamıştır. Her katılımcıya özel düzeltici egzersizler ön testte elde edilen toplam tarama skorları doğrultusunda FHT'nin egzersiz kütüphanesinden belirlenen ve katulımcının problemli olduğu tespit edilen hareketlere yönelik olarak şeçilen düzeltici egzersiz programı uygulanmıştır. Protokolde yer alan egzersizlerin set ve tekrar sayıları ilk 2 hafta $2 \times 10$; sonraki 3 hafta $3 \times 10$ ve son 3 hafta $3 \times 12$ olarak düzenlenmiştir. Her bir katılımcıya uygulanan bireysel egzersiz programlarından bir katıllmcıya ait örnek aşağıda verilmiştir.

\begin{tabular}{|c|c|c|}
\hline Hedef Hareket & Düzeltici Egzersiz & Açıklama \\
\hline Derin Çömelme & Deep Squat Assisted With FMT & Squat model hareketliğinin artırılmasına yardımcı olur. \\
\hline Yüksek Adımlama & $\begin{array}{l}\text { Single Leg Stance With Core } \\
\text { Engagement with Cable System }\end{array}$ & $\begin{array}{l}\text { Tek bacaklı duruşta kaliteli zamanlamayı, hareketliliği ve istikrarı } \\
\text { artırır. }\end{array}$ \\
\hline Tek Çizgide Hamle & $\begin{array}{l}\text { Dorsiflexion from Half Kneeling } \\
\text { with Dowel }\end{array}$ & Ayak bileği hareketliliğini geliştirmeye yardımcı olmaktadır. \\
\hline $\begin{array}{l}\text { Aktif Düz Bacak } \\
\text { Kaldrma }\end{array}$ & Active Leg Lowering To Bolster & $\begin{array}{l}\text { Aktif düz bacak kaldırma hareketi için kalça hareketliliğini ve } \\
\text { stabiliteyi bir destek kullanarak iyileştirecektir. }\end{array}$ \\
\hline $\begin{array}{l}\text { Gövde Stabilite } \\
\text { Şınav1 }\end{array}$ & Push-Up Walkout & $\begin{array}{l}\text { Lumbopelvik kontrol ve omurga stabilizesi için dinamik bir } \\
\text { motor kontrol etmeyi amaçlayan bir drilidir. }\end{array}$ \\
\hline Rotasyon Stabilitesi & $\begin{array}{l}\text { Dorsiflexion Resisted Ball Roll With } \\
\text { Core Activation With FMT }\end{array}$ & $\begin{array}{l}\text { Tam bir kalça, diz ve ayak bileği hareketliliği aracıllğıyla } \\
\text { dorsifleksiyonu geliştirmeye yardımci olur. }\end{array}$ \\
\hline
\end{tabular}

\subsection{Verilerin Analizi}

Tüm veriler SPSS 22.0 istatistik paket programına girildikten sonra katılımcılarının fiziksel özelliklerinin tanımlayıcı istatistiği yapılmıştır. Katılımcıların FHT ve DMT skorları ön testleri ile son testleri arasındaki farkları non-parametrik terslerden Wilcoxon İşaretli Sıralar Testi ile belirlenmiştir. Çalışmada anlamlılık düzeyi $\mathrm{p}<0,05$ olarak kabul edilmiştir.

\section{Bulgular}

Tablo 1. Düzeltici egzersiz grubu, basketbol grubu ve kontrol grubu katılımcilarının fiziksel özellikleri

\begin{tabular}{|c|c|c|c|c|c|c|}
\hline & \multicolumn{2}{|c|}{$K G(n=25)$} & \multicolumn{2}{|c|}{ BG $(n=20)$} & \multicolumn{2}{|c|}{ DEG $(n=20)$} \\
\hline Değişkenler & Ön-Test & Son-Test & Ön-Test & Son-Test & Ön-Test & Son-Test \\
\hline Boy $(\mathrm{m})$ & $1,52 \pm 0,05$ & $1,53 \pm 0,05$ & $1,51 \pm 0,11$ & $1,53 \pm 0,11$ & $1,52 \pm 0,10$ & $1,54 \pm 0,09$ \\
\hline Vücut ağırllı̆̆1 (kg) & $46,52 \pm 9,03$ & $47,00 \pm 8,46$ & $55,36 \pm 21,22$ & $53,95 \pm 19,04$ & $46,70 \pm 7,52$ & $47,24 \pm 7,50$ \\
\hline VKİ $\left(\mathrm{kg} / \mathrm{m}^{2}\right)$ & $20,03 \pm 3,17$ & $20,05 \pm 2,88$ & $23,27 \pm 6,20$ & $22,25 \pm 4,93$ & $20,05 \pm 3,05$ & $19,72 \pm 2,69$ \\
\hline
\end{tabular}

Tablo 2. Grupların FHT ön test ve son test ölçüm değerlerinin karşılaştırıldığı Wilcoxon işaretli siralar testi

\begin{tabular}{|c|c|c|c|c|c|c|c|c|c|}
\hline \multirow[b]{2}{*}{ Değişkenler } & \multicolumn{3}{|c|}{ KG (n=25) } & \multicolumn{3}{|c|}{ BG $(n=20)$} & \multicolumn{3}{|c|}{ DEG $(n=20)$} \\
\hline & $\overline{\text { Ön-Test }}$ & Son-Test & $\mathrm{p}$ & $\overline{\text { Ön-Test }}$ & Son-Test & $\bar{p}$ & Ön-Test & Son-Test & $\overline{\mathrm{p}}$ \\
\hline Derin Çömelme & $1,76 \pm 0,43$ & $1,80 \pm 0,40$ & 0,31 & $1,45 \pm 0,51$ & $1,45 \pm 0,51$ & $\frac{1}{1,00}$ & $1,50 \pm 0,51$ & $2,50 \pm 0,68$ & 0,00 \\
\hline Yüksek Adımlama & $1,64 \pm 0,48$ & $1,72 \pm 0,54$ & 0,15 & $1,25 \pm 0,55$ & $1,60 \pm 0,68$ & 0,03 & $1,00 \pm 0,00$ & $2,10 \pm 0,44$ & 0,00 \\
\hline Tek Çizgide Hamle & $1,72 \pm 0,73$ & $1,84 \pm 0,74$ & 0,18 & $1,40 \pm 0,59$ & $1,55 \pm 0,51$ & 0,18 & $1,25 \pm 0,44$ & $2,25 \pm 0,55$ & 0,00 \\
\hline Omuz Mobilitesi & $1,52 \pm 0,65$ & $1,52 \pm 0,58$ & 1,00 & $2,05 \pm 0,82$ & $2,05 \pm 0,82$ & 1,00 & $2,15 \pm 0,87$ & $2,65 \pm 0,58$ & 0,01 \\
\hline Aktif Düz Bacak Kaldrma & $1,60 \pm 0,70$ & $1,56 \pm 0,65$ & 0,31 & $1,80 \pm 0,83$ & $1,75 \pm 0,85$ & 0,70 & $1,25 \pm 0,44$ & $2,40 \pm 0,59$ & 0,00 \\
\hline Gövde Stabilite Șınavı & $1,44 \pm 0,50$ & $1,44 \pm 0,50$ & 1,00 & $1,10 \pm 0,30$ & $1,30 \pm 0,47$ & 0,46 & $1,10 \pm 0,30$ & $2,10 \pm 0,78$ & 0,00 \\
\hline Rotasyon Stabilitesi & $1,72 \pm 0,45$ & $1,72 \pm 0,45$ & 1,00 & $1,10 \pm 0,30$ & $1,20 \pm 0,41$ & 0,31 & $1,72 \pm 0,45$ & $1,76 \pm 0,43$ & 0,00 \\
\hline FHT Toplam Skoru & $11,40 \pm 1,95$ & $11,48 \pm 1,98$ & 0,58 & $9,75 \pm 2,93$ & $10,85 \pm 2,08$ & 0,00 & $9,45 \pm 1,63$ & $15,80 \pm 1,79$ & 0,00 \\
\hline
\end{tabular}


Usluer, Ș. N., Aktuğ, Z. B., İbiş, S., \& Aka, H. (2021). Düzeltici egzersizlerin fonksiyonel hareket tarama testi ve motor beceri üzerine etkisi. Journal of Human Sciences, 18(3), 390-399. doi:10.14687/jhs.v18i3.6154

Tablo 2 incelendiğinde DEG'da FHT alt değişkenleri ve FHT toplam skoru ön test ile son test sonuçları arasında son test lehine anlamlı farklılık tespit edilmiştir $(\mathrm{p}<0,05)$. BG'da FHT yüksek adımlama ve FHT toplam skoru ön test ile son testleri arasında son test lehine istatiksel olarak anlamlı fark belirlenmiştir $(\mathrm{p}<0,05)$. KG'da ise katılımcıların ön test ile son testleri arasinda istatiksel olarak anlamlı bir fark bulunmamıştır $(\mathrm{p}<0,05)$.

Tablo 3. Grupların FHT ön test ve son test ölçüm değerlerinin karşılaştırıldığ1 Wilcoxon işaretli siralar testi

\begin{tabular}{|c|c|c|c|c|c|c|c|c|c|}
\hline \multirow[b]{2}{*}{ Değişkenler } & \multicolumn{3}{|c|}{$K G(n=25)$} & \multicolumn{3}{|c|}{ BG $(n=20)$} & \multicolumn{3}{|c|}{ DEG $(n=20)$} \\
\hline & Ön-Test & Son-Test & $\mathrm{p}$ & Ön-Test & Son-Test & $\mathrm{p}$ & Ön-Test & Son-Test & $\mathrm{p}$ \\
\hline DMT $_{20 \mathrm{~m} \text { Sprint }}$ & $2,04 \pm 1,33$ & $2,16 \pm 1,24$ & 0,48 & $1,90 \pm 1,29$ & $1,90 \pm 1,25$ & 1,00 & $1,70 \pm 1,03$ & $1,75 \pm 1,16$ & 0,88 \\
\hline DMT Yana Siçrama & $2,52 \pm 1,19$ & $2,52 \pm 1,29$ & 1,00 & $2,90 \pm 0,91$ & $3,55 \pm 0,94$ & 0,00 & $2,95 \pm 1,57$ & $3,85 \pm 1,22$ & 0,00 \\
\hline $\mathrm{DMT}_{\text {Esneklik }}$ & $2,68 \pm 1,28$ & $2,52 \pm 1,29$ & 0,20 & $3,25 \pm 1,25$ & $3,55 \pm 1,27$ & 0,25 & $2,70 \pm 1,49$ & $4,10 \pm 1,02$ & 0,00 \\
\hline DMT Durarak Uzun Atlama & $1,04 \pm 0,20$ & $1,12 \pm 0,33$ & 0,15 & $1,00 \pm 0,00$ & $1,05 \pm 0,22$ & 0,31 & $1,15 \pm 0,48$ & $1,60 \pm 0,88$ & 0,04 \\
\hline DMT Mekik & $1,28 \pm 0,61$ & $1,24 \pm 0,59$ & 0,31 & $1,80 \pm 0,95$ & $2,15 \pm 1,08$ & 0,02 & $1,15 \pm 0,36$ & $2,25 \pm 1,16$ & 0,00 \\
\hline DMT Denge & $2,76 \pm 1,36$ & $2,64 \pm 1,28$ & 0,31 & $2,00 \pm 1,07$ & $2,05 \pm 1,27$ & 0,81 & $2,10 \pm 1,33$ & $3,75 \pm 0,91$ & 0,00 \\
\hline $\mathrm{DMT}_{\text {Şinav }}$ & $3,08 \pm 1,41$ & $3,08 \pm 1,46$ & 1,00 & $3,25 \pm 1,06$ & $3,55 \pm 1,43$ & 0,27 & $3,35 \pm 1,69$ & $4,05 \pm 1,27$ & 0,00 \\
\hline DMT 6 dk Koşu & $1,00 \pm 0,00$ & $1,00 \pm 0,00$ & 1,00 & $1,65 \pm 1,18$ & $1,80 \pm 1,15$ & 0,08 & $1,50 \pm 0,88$ & $1,70 \pm 0,86$ & 0,24 \\
\hline DMT Toplam Skor & $16,40 \pm 3,58$ & $16,28 \pm 3,51$ & 0,58 & $17,90 \pm 3,35$ & $19,65 \pm 4,01$ & 0,00 & $16,60 \pm 5,49$ & $23,10 \pm 5,06$ & 0,00 \\
\hline
\end{tabular}
$*_{\mathrm{p}}<0,05$

Tablo 3 incelendiğinde DEG'da DMT yana sıçrama, DMT esneklik, DMT durarak uzun atlama, DMT mekik, DMT denge, DMT şınav ve DMT toplam skor değerlerinin son testte istatiksel olarak anlamlı şekilde arttı̆̆1 belirlenmiştir $(\mathrm{p}<0,05)$. BG'da DMT yana sıçrama, DMT mekik, DMT toplam skor değerlerinin son testte istatiksel olarak anlamlı şekilde arttığ1 tespit edilmiştir $(\mathrm{p}<0,05)$. KG'da ise ön test ile son test değerleri arasında istatiksel olarak anlamlı bir fark bulunmamıştır $(\mathrm{p}<0,05)$.

Tablo 4. Katılımcı grupların FHT toplam skor ve DMT toplam skor ön test - son test yüzdelik artış tablosu

\begin{tabular}{lcc}
\hline \multicolumn{1}{c}{ Gruplar } & $\mathbf{\%}$ & $\boldsymbol{\%}$ \\
\hline & FHT Toplam Skoru & DMT Toplam Skoru \\
\hline Düzeltici Egzersiz Grubu (20) & 55,70 & 42,22 \\
\hline Basketbol Grubu (20) & 16,25 & 34,83 \\
\hline Kontrol Grubu (25) & 5,20 & 8,24 \\
\hline
\end{tabular}

Tablo 4 incelendiğinde FHT toplam skorunun son testte DEG'da \% 55,70 BG'da \%16,25 ve KG'da \%5,20 artığ1 görülmüştür. Ayrıca DMT toplam skorunun son testte DEG'da \% 42,22 BG'da $\%$ 34,83 ve KG'da \%8,24 artı̆̆ belirlenmiştir.

\section{Tartışma}

Fonksiyonel bir hareket kalıbı doğru şekilde uygulanamadığında hareketlerde işlevsel bozulmalar meydana gelebilir. Fonksiyonel hareket kalıbındaki işlevsizlikler ise kas kuvvetindeki dengesizlik, nöromüsküler kontroldeki eksiklikler veya asimetrilerden kaynaklanır ve bu durum fiziksel performansta kayıplara yol açabilir (Cook ve ark., 2006; Cook ve ark., 2014). Fonksiyonel hareketleri değerlendiren birçok çalışmada FHT alt testleri ve toplam skorlarındaki düşük puanların ve asimetrilerin, sporcularda performansı sinırlandırdığ1 ve yaralanma olasilıklarını artırdığ1 belirtilmektedir (Kiesel ve ark., 2007; Kiesel ve ark., 2008; Chorba ve ark., 2010). Buradan hareketle çalışmamızın amacı 12-15 yaşları arasındaki basketbolculara uygulanan 8 haftalık düzeltici egzersizlerin, FHT test sonuçlarına ve MB’leri üzerine etkisinin incelenmesidir.

\subsection{Düzeltici Egzersizlerin Fonsiyonel Hareket Tarama Testi Üzerine Etkisi}

Çalışmamızda katılımcıların FHT alt testleri ve toplam puanlanının yapılan istatistiksel analiz sonuçlarına göre, KG'nun test sonuçlarında anlamlı fark bulunmazken; yalnızca basketbol 
Usluer, Ş. N., Aktuğ, Z. B., İbiş, S., \& Aka, H. (2021). Düzeltici egzersizlerin fonksiyonel hareket tarama testi ve motor beceri üzerine etkisi. Journal of Human Sciences, 18(3), 390-399. doi:10.14687/jhs.v18i3.6154

antrenmanı uygulayan grubun, FHT alt testlerinden yüksek adımlama ve FHT toplam skorunun son testte anlamlı olarak arttığı belirlenmiştir. Bu durumun top sürme, turnike ve ribaund gibi basketbola özgü tekniklerin sıklıkla uygulanmasına bağlı olarak yüksek adımlama alt test puanlarını artırmıs olabileceği düşünülmektedir. Ayrıca FHT toplam puanındaki artış ise antrenman programlarında fonksiyonel hareket kalıplarını geliştirmeye yönelik egzersizlere yer verilmesinden kaynaklanabilir.

Basketbol antrenmanlarına ilaveten düzeltici egzersizler uygulayan grubun analiz sonuçları incelendiğinde ise FHT alt testlerinin tamaminda ve FHT toplam skorunda son testte istatistiksel olarak anlamlı bir artış olduğu tespit edilmiştir. Bu sonuç genç sporculara uygulanan düzeltici egzersizlerin sporcularda fonksiyonel hareket paternlerini geliştireceği hipotezini doğrular niteliktedir. Genç sporcuların bu dönemde doğru hareket kalıplarını uygulamaları, sporculuk yaşantısı boyunca performansı artırıken, yaralanma riskini de azalttı̆̆ı şeklinde değerlendirilebilir.

Literatürde uygulanan düzeltici egzersizlerin, FHT test sonuçlarına etkisini inceleyen çalışmaların sınırlı sayıda olduğu görülmektedir. Aktuğ ve ark. (2019) tarafindan yapılan bir çalışmada, elit kadın voleybolculara 12 hafta boyunca uygulanan düzeltici egzersizlerin, sporcularda FHT alt testlerinden omuz mobilitesi ve FHT toplam puanlarını son testte artırdığını bulmuşlardır. Ayrıca aynı çalışmada FHT alt testlerindeki diğer sonuçlarda da istatistiksel olarak anlamlı fark olmamasına rağmen, gelişme olduğu belirlenmiş ve düzeltici egzersiz programlarının antrenman içeriklerine yerleştirilmesinin sporcuların yaralanma risklerini azaltabileceğini belirtilmiştir. Campa ve ark. (2019) genç elit erkek futbolcular üzerine yaptı̆̆ bir çalısmada 20 hafta boyunca uygulanan düzeltici egzersiz programının FHT toplam skorunda artış sağladığını tespit etmişlerdir. Ayrıca Campa ve ark. (2019) genç elit futbolcuların FHT ön test sonuçlarında yüksek oranda asimetrik hareketler sergilediklerini ve uygulanan düzeltici egzersiz programı ile fonksiyonel hareket kalıplarının da son testte geliştirildiğini bulmuşlardır. Stanek ve ark. (2017) benzer bir çalışmada, itfaiyecilere uygulanan 8 haftalık kişiselleştirilmiş düzeltici egzersiz programının FHT toplam skorunu son testte anlamlı olarak artırdığını, temel hareketlerdeki işlevsel bozuklukları geliştirebileceğini ve yaralanmaları önleyebileceğini belirtmişlerdir. Tejani ve ark. (2019) kadın sporcuların (futbol, softbol, basketbol) fonksiyonel hareket paternlerini geliştirmek için standartlaştırılmış bir egzersiz programı ile düzeltici egzersiz programı uygulamış ve katılımcıların FHT sonuçlarının önemli derecede arttığını belirlemişlerdir. Kiesel ve ark. (2011) yaptıkları bir çalışmada, profesyonel futbolculara uygulanan düzeltici egzersiz programı sonucunda FHT toplam puanının son testte geliştiğini saptamışlardır.

Yukarıda belirtilen çalışmalarda farklı yaş, cinsiyet ve spor branşlarından sporculara uygulanan düzeltici özel egzersiz programlarının sporcularda fonksiyonel hareket kalıplarını geliştirerek FHT puanlarını artırması, sonuçlarımızın doğruluğunu destekler niteliktedir. Sporcularda düzeltici egzersizlerin bir süreç içerisinde uygulanmasının sistematik bir şekilde fonksiyonel hareketliliği geliştirdiği belirtilmektedir (Clark ve Lucett, 2010). Fonksiyonel hareketliliğin artmasının sporcularda performans gelişiminde ve yaralanmaların önlenmesinde etkili bir faktör olacağı düşünülmektedir.

\subsection{Düzeltici Egzersizlerin Motor Beceri Üzerine Etkisi}

Çalışmamızda düzeltici egzersiz programı uygulayan grubun MB parametrelerine bakıldığında; DMT yana sıçrama, DMT esneklik, DMT durarak uzun atlama, DMT mekik, DMT denge, DMT şınav, DMT toplam skorlarının ön test ile son testleri arasında son test lehine anlamlı fark bulunmuştur. Bu sonucun sporculara uygulanan düzeltici egzersizlerin sporcularda kuvvet, denge ve kontrol becerilerini geliştirmesinden kaynaklanmış olabileceği düşünülmektedir.

Basketbol grubunda bulunan sporcuların MB test sonuçları incelendiğinde DMT yana sıçrama, DMT mekik ve DMT toplam skorlarının ön test ve son test değerleri arasında son test lehine anlamlı fark belirlenmiştir. Basketbol antrenmanı uygulayan grubun son testte gelişen MB paremetrelerinin basketbol oyun karekterine uygun nitelikte hareketler olduğu dikkat çekmektedir. Nitekim basketbolcuların sıçrama performansının oyunda önemli bir belirteç olması; elde edilen gelissimin sıçrama gibi hareketlerin sık uygulanmasının bir sonucu olabilir. Kontrol grubunun MB testinin analiz sonuçlarına göre ise DMT alt skorları ön test ile son testleri arasında istatiksel olarak anlamlı bir fark bulunmamıştır. 
Usluer, Ş. N., Aktuğ, Z. B., İbiş, S., \& Aka, H. (2021). Düzeltici egzersizlerin fonksiyonel hareket tarama testi ve motor beceri üzerine etkisi. Journal of Human Sciences, 18(3), 390-399. doi:10.14687/jhs.v18i3.6154

Literatürde düzeltici egzersizlerin $\mathrm{MB}$ üzerine etkisini araştıran bir çalışma bulunmaması çalışmamızın özgünlüğü olarak değerlendirilse de sonuçlarımızın karşılaştırılmasını sınırlandırmıştır. Motor beceri ile FHT sonuçlarını araştıran ise sadece bir çalışma bulunmaktadır. Silva ve ark. (2019) tarafindan yapılan motor yeterlilik ve FHT sonuçlarına yönelik çalışmada, motor yeterlilik ve fonksiyonel hareket taraması test sonuçları arasında pozitif yönlü anlamlı ilişki olduğu tespit etmiştir. Bu çalışma sonucunda motor yeterlilik ve FHT sonuçları arasında belirlenen anlamlı ilişki, fonksiyonel hareket kalıplarındaki işlevsizlik ve asimetrilerin aynı zamanda motor yeterliliği de kısıtlamasından kaynaklanmış olabilir. Dolayısıyla çalışmamızda uygulanan düzeltici egzersizlerin fonksiyonel hareketlerdeki işlevsizliği önlemesi ve MB performansı geliştirmesi Silva ve ark. (2019) çalışma sonuçlarını destekler niteliktedir.

Literatürde MB'lerin zeka, yaş, genel motivasyon kayg1sı, yorgunluk, çevresel faktörler ve spora katılım düzeyi (kondisyon düzeyi, antrenman durumu) gibi birçok faktör ile yakından ilişkili olduğunu belirten çalşmalar bulunmaktadır (Timmons ve ark., 2007; Sayın, 2011; İri ve Aktuğ, 2017). Motor beceriyi geliştirici faktörlerden birisinin de spor olduğu bilinmektedir.

Yukarıda belirtilen çalışmaların odak noktası MB ile sportif performansın birbirini geliştirici niteliğe sahip olduğudur. Dolayısıyla çalışma sonucumuzda düzeltici egzersizlerin MB'yi geliştirmesi de beklenen bir durumdur ve yukarıda belirtilen çalışma sonuçlarını destekler niteliktedir.

Çalışmamızda değerlendirilen bir diğer değişken grupların ön test - son test DMT toplam skor ve FHT toplam skor gelişimlerinin yüzdelik değerleridir. Yapılan istatistiksel analiz sonuçlarına bakıldığında hem DMT hem de FHT toplam puanlarında en yüksek yüzdelik artışın sırası ile DEG, $B G$ ve $K G$ olarak sıralandığ 1 tespit edilmiştir. Bu sonuç genç sporculara uygulanan düzeltici egzersizlerin fonksiyonel hareket paternlerini geliştirdiği, bu gelişimin de FHT toplam skoru ve MB gelişimine yansıdığını düşündürmektedir. Genç sporculara uygulanan düzeltici egzersizlerin spor yaralanmalarının önlenmesinde koruyucu strateji olmasının yanı sira sportif performansın da artmasını sağlayacağı söylenebilir.

Çalışmamızın sonuçlarına göre, genç sporculara uygulanan branşa özgü antrenmanların fonksiyonel hareket kalıpları ve MB gelişimine katkısının sınırlı olduğu, branşa özgü antrenmanlara ilaveten uygulanan düzeltici egzersizlerin ise fonksiyonel hareket paternlerini geliştirdiği ve MB'lerini daha fazla artırdığı tespit edilmiştir. Özellikle alt yap1 sporcularının doğru hareket kalıplarının oluşmasında ve MB'lerinin gelişmesinde düzeltici egzersizlerin hayati bir öneme sahip olduğu söylenebilir. Antrenörlerin sporcularda fonksiyonel hareketlerdeki işlevsizlikleri ve asimetrileri düzeltmek istediği durumlarda antrenman programlarına düzeltici egzersizleri ilave etmeleri önerilebilir.

\section{Teşekkür}

Fonksiyonel Hareket Tarama Testinin uygulanması ve yorumlanmasında katkılarından dolay1 Emre Altundağ’a teşekkür ederiz.

\section{Kaynaklar}

Aktuğ, Z. B., Aka, H., Akarçeşme, C., Çelebi, M. M., \& Altundă̆g, E. (2019). Elit kadın voleybolcularda düzeltici egzersizlerin fonksiyonel hareket taraması test sonuçlarına etkileri. Spor Hekimliği Dergisi, 54(4), 233-241.

Bös, K., Schlenker, L., Büsch, D., Lammle, L., Müller, H., Oberger, J., \& Tittlbach, S. (2009). Deutscher motorik-test 6-18 (DMT 6-18). Hamburg: Czwalina.

Brukner, P. (2012). The younger athlete. In: Maffuli, N., Caine, D. (eds.) Brukner\& Khan's Clinical Sports Medicine. 4th ed. Australia: McGraw-Hill.

Campa, F., Spiga, F., \& Toselli, S. (2019). The effect of a 20-week corrective exercise program on functional movement patterns in youth elite male soccer players. Journal of Sport Rehabilitation, 28(7), 746-751. 
Usluer, Ș. N., Aktuğ, Z. B., İbiş, S., \& Aka, H. (2021). Düzeltici egzersizlerin fonksiyonel hareket tarama testi ve motor beceri üzerine etkisi. Journal of Human Sciences, 18(3), 390-399. doi:10.14687/jhs.v18i3.6154

Cattuzzo, M. T., Henrique, R. S., Ré, A. H. N., Oliveira, I. S., Melo, B. M., Moura, M., de Araújo, R.C., \& Stodden, D.F. (2016). Motor competence and health related physical fitness in youth: A systematic review. Journal of Science and Medicine in Sport, 19(2), 123-129.

Chorba, R. S., Chorba, D. J., Bouillon, L. E., Corey, A. O., \& James, A. L. (2010). Use of a functional movement screening tool to determine injury risk in female collegiate athletes. North American Journal Sports Physical Therapy, 5(2), 47-54.

Clark, M., \& Lucett, S. (2010). Essentials of corrective exercise training. Philadelphia: Pa. Lippincott Williams \& Wilkins.

Cook, G., Burton, L., Hoogenboom, B. J., \& Voight M. (2014). Functional movement screening: The use of fundamental movements as an assessment of function- Part 1. International Journal of Sports Physical Therapy, 9(3), 396-409.

Cook, G., Burton, L., \& Hoogenboom, B. (2006). Pre-participation screening: The use of fundamental movements as an assessment of function-Part 1. North American Journal of Sports Physical Therapy, 1(2), 62-72.

Haga, M. (2008). The relationship between physical fitness and motor competence in children. Child: Care Health and Development, 34, 329-334

Hamilton, N., Weimar, W., \& Luttgens, K. (2002). Kinesiology. Scientific basis of human motion. 12th ed. New York: McGrew-Hill Comparies Inc.

Henderson, S.E., \& Sugden, D.A. (1992). The movement assessment battery for children: Manual. London: The Psychological Corporation.

İri, R., \& Aktuğ, Z. B. (2017). Investigating the effect of sports on motor skills in children. Journal of Human Sciences, 14(4), 4300-4307.

Kiesel, K., Plisky, P. \& Kersey, P. (2008). Functional movement test score as a predictor of time-loss during a professional football team's pre- season. American College of Sports Medicine Annual Conference, Indianap.

Kiesel, K., Plisky, P., \& Butler, R. (2011). Functional movement test scores improve following a standardized off-season intervention program in professional football players. Scandinavian Journal of Medicine Science Sports, 21, 287-292.

Kiesel, K., Plisky P. J., \& Voight M. L. (2007). Can serious injury in professional football be predicted by a preseason functional movement screen? North American Journal of Sports Physical Therapy, 2(3), 147-158.

Kraus, K., Schütz, E., Taylor, W. R., \& Doyscher, R. (2014). Efficacy of the functional movement screen: A review. The Journal of Strength and Conditioning Research, 28(12), 3571-3584.

Minick, K. I., Kiesel, K. B., Burton, L. E. E., Taylor, A., Plisky, P., \& Butler, R. J. (2010). Interrater reliability of the functional movement screen. The Joumal of Strength and Conditioning Research, 24(2), 479-486.

Mirhadi, S., Ashwood, N., \& Karagkevrekis, B. (2015). Review of snowboarding injuries. Trauma, 17(3), 175-80.

Mokha, M., Sprague, P. A., \& Gatens, D. R. (2016). Predicting musculoskeletal injury in national collegiate athletic association division II athletes from asymmetries and individual-test versus composite functional movement screen scores. Journal of Atbletic Training, 51(4), 276-82.

O’Kane, J. W., Neradilek, M., Polissar, N., Sabado, L., Tencer, A., \& Schiff, M. A. (2017). Risk factors for lower extremity overuse injuries in female youth soccer players. Orthopaedic Journal of Sports Medicine, 5(10), 2325967117733963.

Onate, J. A., Dewey, T., Kollock, R. O., Thomas, K. S., Van Lunen, B. L., DeMaio, M., \& Ringleb, S. I. (2012). Real-time intersession and interrater reliability of the functional movement screen. The Journal of Strength and Conditioning Research, 26(2), 408-415.

Patel, D. R., Yamasaki, A., \& Brown, K. (2017). Epidemiology of sports-related musculoskeletal injuries in young athletes in United States. Translational Pediatrics, 6(3), 160-166.

Pişkin, N. E., Şengür, E., Aktuğ, Z. B. (2020). Çocuklarda yaz spor okullarının motor beceri üzerine etkisinin incelenmesi. İnönü Üniversitesi Beden Eğitimi ve Spor Bilimleri Dergisi, 7(1), 25-36. 
Usluer, Ş. N., Aktuğ, Z. B., İbiş, S., \& Aka, H. (2021). Düzeltici egzersizlerin fonksiyonel hareket tarama testi ve motor beceri üzerine etkisi. Journal of Human Sciences, 18(3), 390-399. doi:10.14687/jhs.v18i3.6154

Robinson, L. E., Stodden, D. F., Barnett, L. M., Lopes, V. P., Logan, S. W., Rodrigues, L. P., \& D'Hondt, E. (2015). Motor competence and its effect on positive developmental trajectories of health. Sports Medicine, 45(9), 1273-1284.

Sayın, M. (2011). Hareket ve beceri ögrenimi. Ankara: Spor Yayınevi ve Kitapevi.

Silva, B., Rodrigues, L. P., Clemente, F. M., Cancela, J. M., \& Bezerra, P. (2019). Association between motor competence and functional movement screen scores. Peer Journal, 7, e7270.

Stanek, J. M., Dodd, D. J., Kelly, A. R., Wolfe, A. M., \& Swenson, R. A. (2017). Active duty firefighters can improve functional movement screen (fms) scores following an 8-week individualized client workout program. Work Journal, 56(2), 213-220.

Stodden, D. F., Goodway, J. D., Langendorfer, S. J., Roberton, M. A., Rudisill, M. E., Garcia, C., \& Garcia, L. E. (2008). A developmental perspective on the role of motor skill competence in physical activity: An emergent relationship. Quest, 60(2), 290-306.

Tejani, A. S., Middleton, E. F., Huang, M., \& Dimeff, R. J. (2019). Implementing a standardized interventional exercise regimen to improve functional movements in female collegiate athletes. International Journal of Sports Physical Therapy, 14(1), 117-126.

Timmons, B. W., Naylor, P. J., \& Pfeiffer, K. A. (2007). Physical activity for preschool children: How much and how? Canadian Journal of Public Health, 32, 122-134.

\section{Extended English Summary}

Determining the probability of injuries of athletes is very important in terms of developing protective strategies and performance efficiency (Kiesel et al., 2007). Functional Movement Screen test (FMS) is a scanning tool that can be applied quickly and easily in predicting injuries that may occur in athletes. The FMS test battery enables the basic movement patterns in athletes to be reliably evaluated with simple methods (Kraus et al., 2014; Onate et al., 2012; Minick et al., 2010). Limitations, asymmetries and dysfunctions in functional movement patterns are detected in the evaluations made with FMS (Chorba et al., 2010). If the functional movement patterns of the athletes are bad, this restricts the performance of the athlete and may increase the risk of injury (Kiesel et al., 2007). An appropriate level of stability and mobility is required for an efficient functional movement (Hamilton, 2002).

It is thought that developing functional movement patterns of athletes at an early age will ensure the application of correct movement patterns and accordingly performance efficiency. It is known that functional movement patterns can be developed and corrective exercises can also be used to improve functional movement patterns (Mokha et al., 2016). Corrective exercises can reduce the asymmetries in movements with a series of exercises prepared for the functional movement patterns of the athletes which are dsysfuctional (Aktuğ et al., 2019). In addition, it is thought that corrective exercises will improve the basic movement patterns of athletes while at the same time improving their motor skills. It is seen that there are a limited number of studies in the literature investigating the effects of corrective exercises on basic movement patterns (Aktuğ et al., 2019). There is no study on improving motor skills with corrective exercises. In this context, the aim of our study is to examine the effect of corrective exercises applied to young basketball players on FMS and motor skill test scores.

In the study, a control group model including pre-test and post-test measurements, which is one of the experimental models, was used. Participants were divided into Corrective Exercise Group (CEG), Control Group (CG) and Basketball Group (BG) through random method. CEG participants participated in the corrective exercise protocol in addition to their routine training 3 days a week over an 8 -week period. BG participants only participated in the training program at the basketball summer school during this period. No application has been made to CG. The purpose of dividing the participants into three groups is to determine whether the developments that may occur according to the hypothesis of the study are due to the developmental stages of the children, the basketball training or the result of the corrective exercises applied. 
Usluer, Ș. N., Aktuğ, Z. B., İbiş, S., \& Aka, H. (2021). Düzeltici egzersizlerin fonksiyonel hareket tarama testi ve motor beceri üzerine etkisi. Journal of Human Sciences, 18(3), 390-399. doi:10.14687/jhs.v18i3.6154

The population of the study consists of sedentary children aged 12-15 in Niğde and children aged 12-15 who attended the summer school in the Youth Services and Sports Club affiliated to the Niğde Youth and Sports Provincial Directorate. The sample was 65 sedentary selected from the accessible population and children who attended the basketball summer school.

Functional movement patterns of children were determined by FMS test and motor skills with Deutscher Motor Test (DMT). Special corrective exercises program selected for the movements determined from the exercise library of the FMS and found to be problematic for the participant in accordance with the total screening scores obtained in the pre-test were applied to each participant. The number of sets and repetitions of the exercises in the protocol is $2 \times 10$ for the first 2 weeks, $3 \times 10$ for the next 3 weeks and $3 \times 12$ for the last 3 weeks. The Wilcoxon Signed-Ranks Test was used to determine the difference between the children's pre-tests of FMS scores and DMT scores and their post-tests after corrective exercises.

In our study, according to the statistical analysis results of the FMS subtests and total scores of the participants, there was no significant difference in the test results of the control group. It was determined that the high pacing and FMS total scores of the FMS subtest hurdle step of the group that only practiced basketball training significantly increased in the posttest. It is thought that this situation may have increased the high stepping subtest scores due to the frequent application of basketball-specific techniques such as dribbling, tourniquet and rebound. In addition, the increase in FMS total score may be due to the inclusion of exercises aimed at developing functional movement patterns in training programs.

When the analysis results of the group who applied corrective exercises in addition to basketball training were examined, it was found that there was a statistically significant increase in all of the FMS subtests and the FMS total score in the posttest $(\mathrm{p}<0.05)$. This result confirms the hypothesis that corrective exercises applied to young athletes will improve functional movement patterns in athletes. While young athletes applying the correct movement patterns during this period affect the performance positively in the adult sports period, it can also be considered as a low risk of injury.

According to the results of our study, it was determined that branch-specific training applied to young athletes had a limited contribution to functional movement patterns and motor skills development, while corrective exercises applied in addition to branch-specific training improved functional movement patterns and increased their motor skills more. It can be said that corrective exercises have a vital importance in the formation of correct movement patterns and development of motor skills, especially of the younger athletes. In cases where trainers want to correct dysfunctions and asymmetries in functional movements in athletes, it may be recommended to add corrective exercises to their training programs. 